\title{
Inverse Distribution of Pink Macules and Patches
}

Austin Smith, MD; Brittany Blaise, MD; Morgan L. Wilson, DVM, MD; Sacharitha Bowers, MD

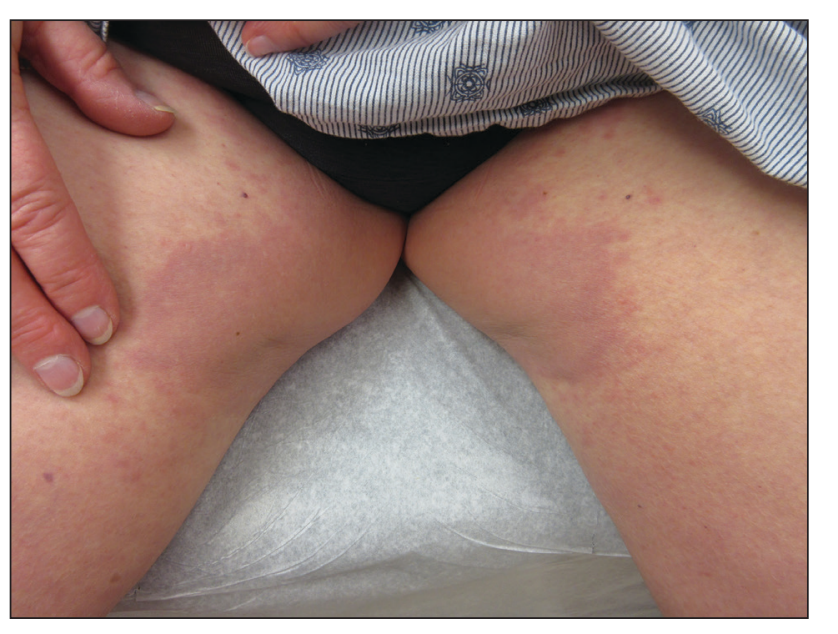

A 73-year-old woman presented for evaluation of an asymptomatic progressive rash on the left wrist, waist, groin, and inner thighs of 2 months' duration. Her primary care provider prescribed clotrimazole and fluconazole with no improvement. Review of systems was negative. Medications included omeprazole, candesartanhydrochlorothiazide, potassium chloride, and levothyroxine. Physical examination revealed many scattered, pink to violaceous macules and patches in the axillae (sparing the vaults) and inguinal folds as well as on the waist and medial upper thighs. The lesions were without scale or other epidermal change. She also had a pink papule on the left volar wrist. A Wood lamp examination was unremarkable, and punch biopsies were performed.

\section{WHAT'S YOUR DIAGNOSIS?}

\author{
a. cutaneous B-cell lymphoma \\ b. granuloma annulare \\ c. psoriasis \\ d. sarcoidosis \\ e. tinea corporis
}

Dr. Smith is from the Intermountain Medical Center, Murray, Utah. Drs. Blaise, Wilson, and Bowers are from the Division of Dermatology, Southern Illinois University School of Medicine, Springfield. 


\section{THE DIAGNOSIS:}

\section{Granuloma Annulare}

$\mathrm{P}$ unch biopsies from the right axilla (Figure) and right abdomen as well as a tangential biopsy from the left volar wrist papule showed an interstitial histiocytic infiltrate with focal palisading of histiocytes around central regions with collagen alteration and increased mucin. Grocott-Gomori methenamine-silver stain and acid-fast bacilli smear both were negative for organisms; these findings were consistent with a diagnosis of granuloma annulare (GA).

Granuloma annulare is a noninfectious granulomatous disease of unknown etiology. It most commonly appears as asymptomatic, flesh-colored, pink or violaceous annular patches or thin plaques favoring the trunk and extremities. Granuloma annulare has many documented presentations including generalized, patch, subcutaneous, and perforating forms. It can present as macules, papules, nodules, patches, or plaques. Reported associations include diabetes mellitus, hyperlipidemia, solid organ tumors, systemic infection, and thyroid disease. ${ }^{1}$ Granuloma annulare can occur in any age group but is most common between the ages of 20 and 40 years. ${ }^{2}$

Diagnosis most often is made clinically and can be confirmed by histopathology. Histologic examination most commonly shows histiocytes within the dermis that palisade around a central area of mucin deposition between degenerating collagen fibers. The histiocytes of GA stain positive with vimentin, lysozyme, and CD68. The increased mucin stains with colloidal iron and Alcian blue. Multinucleated giant cells and perivascular lymphocytic infiltrate also are commonly seen. ${ }^{3}$

Cutaneous B-cell lymphoma has a wide range of presentations but usually occurs as hyperpigmented plaques and patches with dermal atrophy. Psoriasis can present in an inverse distribution but will show epidermal changes including scale. Sarcoidosis presents as multiple erythematous plaques and papules and also can be accompanied by erythema nodosum. Tinea corporis likely would have resolved with antifungal treatment.

Many different treatments have been described as effective, including cryosurgery, topical and intralesional corticosteroids, antibiotics, immune modulators, phototherapy, and oral corticosteroids. ${ }^{1}$ We started our patient on triple-antibiotic therapy with rifampin $600 \mathrm{mg}$,

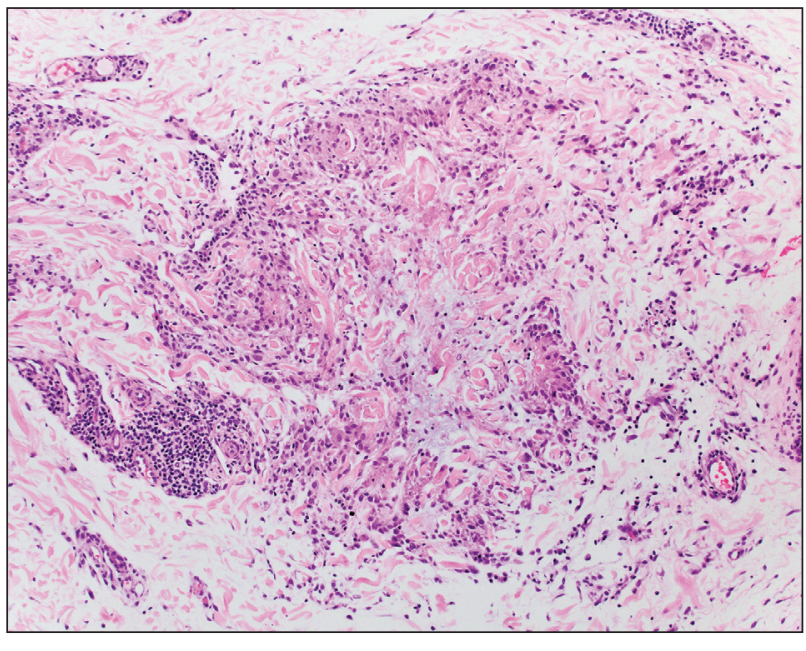

Granuloma annulare. Punch biopsy from the right axilla showed palisaded granuloma with central mucin accumulation (H\&E, original magnification $\times 100)$.

minocycline $100 \mathrm{mg}$, and ofloxacin $400 \mathrm{mg}$ all once monthly for 6 months, which has been shown to be efficacious in treating GA. ${ }^{4}$ The patient returned for follow-up 1 year after the initial presentation. At that time, she had faint pink patches on the waist and medial upper thighs, and the axillary lesions had cleared. In the interim, she developed more classic GA lesions-pink to violaceous smooth papules with no overlying epidermal changes - on the volar wrists and dorsal feet. These lesions were asymptomatic, and she currently is not undergoing any further treatment.

\section{REFERENCES}

1. Piette EW, Rosenbach M. Granuloma annulare: pathogenesis, disease associations and triggers, and therapeutic options. J Am Acad Dermatol. 2016;75:467-479.

2. Piette EW, Rosenbach M. Granuloma annulare: clinical and histologic variants, epidemiology, and genetics. J Am Acad Dermatol. 2016;75:457-465.

3. Patterson JW, Hosler GA. The granulomatous reaction pattern. Weedon's Skin Pathology. 4th ed. China: Churchill Livingstone Elsevier; 2016:198-203.

4. Marcus DV, Mahmoud BH, Hamzavi IH. Granuloma annulare treated with rifampin, ofloxacin, and minocycline combination therapy. Arch Dermatol. 2009; 145:787-789. 